\title{
TERÁ A PERSONIFICAÇÃO DAS SOCIEDADES FUNÇÃO ECONÔMICA?
}

Rachel Sztajn

\begin{abstract}
Resumo:
O texto procura, com base na idéia de pulverização de riscos, demonstrar que a ficção jurídica, ao facilitar a extensão da noção de sujeito de direito a grupos de pessoas uu bens organizados para a obtenção de certos fins socialmente desejáveis, atende a uma necessidade econômica e permite o desenvolvimento de atividades de maior risco. E, por manter em plano secundário essa função, o Código Civil, ao manter a relação biunívoca entre sujeito e patrimônio se distancia do que há de mais atual no direito continental europeu, as sociedades unipessoais.
\end{abstract}

Palavras-chave: Personalidade juridica. Ficção jurídica. Sociedades unipessoais.

\begin{abstract}
:
This paper evidences that legal fictions accomplish economic needs and allow the development of larger risk astivities, by assigning the concept of legal personality to groups of persons or goods arranged to the consecution of certain socially desirable goals, according to the idea of spread of risk. As this role has been in a secondary plan, Brazilian Civil Code, as long as to conserve the relation between subject and assets, moves away the new Europian conception of companies: the one man corporation.
\end{abstract}

Keywords: Legal entity. Legal fiction. One man corporations.

A importância do instituto pessoa jurídica é inegável. Há muito se reconhece. como fuz Washington de Barros Monteiro,' que "Já se disse ulgures tratar-se de tema tormentoso, fascinante e sempre novo. devido às suas múltiplas, variadas $e$ modernas aplicações. Cada dia que passa, novos e imprevistos horizontes se descortinam nesse proteiforme instituto juridico" Ao conceituar pessoas jurídicas explica qui são associações ou instituições criadas para a realização de um fim e reconhecidas como sujeitos pelo Direito.

Alberto Trabucchi ${ }^{2}$ considera a pessoa jurídica um organismo unitário que o ordenamento jurídico qualifica como sujeito de direito. com capacidade juridica própria e distinto das pessoas que concorrem para sua criação.

Professora Associada do Departamento de Direito Comercial da Faculdade de Direito da Universidade de São Paulo.

' MONTEIRO, Washington de Barros. Curso de Direito Civil: parte geral. São Paulo: Saraiva, 1966. v. I. p. 101.

2 TRABUCCHI. Alberto, Istintzioni di Dirino Civile. 40. ed. Padova: Cedam, 2001. p. 111. 
O que interessa é que os sujeitos de direito, sejam eles pessoas naturais ou jurídicas, estão na base da construção de um sistema de normas pois que estas são a eles endereçadas. As pessoas jurídicas, diz Trabuchi, inegavelmente, são criação do direito $e x$ nihilo. Realidade reconhecida na formação social geradas sobre base substancial - pessoas naturais, bens, escopo com atributo formal que é reconhecimento pelo ordenamento jurídico.

Pode-se dizer que as pessoas jurídicas ${ }^{4}$ são fruto da combinação da engenhosidade do homem com o direito, que, por força de seu reconhecimento as incorpora do sistema e que, quanto ao escopo que fomenta sua organização desempenham função socialmente relevante, função esta que se acentua na medida em que se atente para o papel desempenhado no que concerne ao desenvolvimento econômico.

Discorrendo sobre pessoas jurídicas, Francesco Galgano as vê como uma demonstração da soberba do homem diante do Criador, porque esta obra humana. pessoa jurídica, ultrapassa barreiras impostas aos seres humanos como a morte por força de idade, ao mesmo tempo que reproduz alguns atributos humanos como tur filhos, formar famílias, embora não tenha corpo físico. Existem sem serem materiais. As famílias aparecem na formação de subsidiárias, coligadas, controladas. Possivelmente o substrato material necessário para a personificação explique o fato de terem essas criações intelectuais superado, em muito, o que, remotamente, se pretendia. a separação patrimunial.

Varais são as teorias que buscam determinar a natureza jurídica desses especiais sujeitos de direito que, diferentemente das pessoas naturais, não têm existência material, e, mais ainda. podem ạarecer sob diferentes roupagens. A equiparação de certos grupos de pessoas ou conjunto de bens a sujeitos de direito prende-se ao fato de o sistema de normas positivas ocupar-se de indivíduos que são os titulares de direitos c deveres.

Deixa-se de lado a enumeração das várias teorias que procuram explicar ou dar a natureza jurídica desse sujeito de direito, a pessoa jurídica: são elas a da ficção, a da equiparação, a orgânica ou da realidade objetiva, a da realidade das instituições jurídicas, dado que parece haver uma para cada e todo tipo de gosto e corrente de pensamento, para concentrar na teoria da ficção que evolui para a idéia de serem elas mera expressão nominal uu. segundo Alpa. flactus vocis da teoria nominalista. ${ }^{5}$

3 TRABUCCHI, Alberto. Istituzioni di Diritto Civile. 40, ed. Padova: Cedam, 2001. p. 111-112.

- GAlgANO. Francesco, citando Salvatore Satta que afirmara ... l'imenso fenômeno della personaliti giuridica, di questa stupenda creazione umana ... in II Rovescio Del Diritto - Giuffrè Fditore - 1991 - em La Favola della Persona Giuridica - p. 23 e segs.

5 Ob. cit., p. 154. 
É que essa teoria da ficção, mesmo que para muitos estudiosos não seja a melhor, atende ao que se pretende, analisar a função sua econômica. Para isso parte-se de ensinamento de Lon L. Fuller, ${ }^{\circ}$ segundo o qual é preciso compreender ou investigar o que há de ser entendido como ficção jurídica e qual sua utilidade.

O estudioso afirma que a ficção induz a relacionar teoria e fato, conceito e realidade, chamando a atenção para a complexidade dessas relações. Sugere que as ficções, nos sistemas jurídicos, decorrem de serem eles sistemas comprcensivos e de estrutura forte; que o processo institucional que dá eficácia às normas jurídicas nas relações humanas deve apoiar-se na realidade, nos fatos.

Admitir a existência de ficções no direito não significa aceitar a mentira nem falsear a verdade, porque as ficções não se destinam a enganar; são adotadas como "expediente de que se tem consciência de ser uma premissa falsa" " Uma ficção, propõe Fuller, é ou uma declaração de que se tem noção, total ou parcial, de sua falsidade ou uma declaração falsa cuja utilidade é reconhecida. ${ }^{\gamma}$

No que diz respeito à personalidade jurídica, parece que se está no segundo caso. A palavra pessoa. de persunam, significava máscara de teatro e. por extensão, o personagem. Passa-se, por metonímia do personagem para a pessoa. o indivíduo. A pessoa jurídica não é outra coisa que metáfora. Aplicando-se a lei do menor esforço ao processo mental chıga-se a explicação satisfatória para assimilar a pessoa jurídica às pessoas naturais.

Para Fuller as ficções jurídicas refletem processos de complexa especulação das motivações sociais porém a investigação é importante para conhecer as razões ou motivos que levaram à sua criação. Se as ficções permitem reconciliar presunções com resultados, não há dúvida de que, os operadores do direito em Roma, ao estabclecer a presunção de morte do cidadão que participasse de guerras quando sua ausência se prolongasse demasiado, servia para transmitir a herança aos herdeiros. Prescindia-se da prova da morte bastando a ausência para que se garantisse a transmissão do domínio sobre os bens do "presumido falecido"

Afirma Fuller que vantagens das ficções jurídicas são que. conquanto necessárias, podem ser postas de lado assim que se encontre outro mecanismo ou instrumento para chegar ao mesmo resultado por elas propiciado. Fiç̧ões legais, tal como

\footnotetext{
FULLER, Lon L. Legal lictions. Stanford: Stanford I'niversity Press. 1986.

Ob. cil., p. 7.

Ob. cil. p. 9.
} 
as científicas, se destinam a ajustar. compor. eventos ou situações novos com a estrutura conceitual existente.

Ficções, prossegue, são um dos muitos esquemas mentais, tal como as presunções, para redefinir fatos operacionais em relação aos quais algum efeito ¿ pretendido. Assim, pode-se considerar que os fins perseguidos pelas pessoas jurídicas devem ser socialmente descjáveis, funcionalmente indispensáveis para a estabilidade de certas relações jurídicas ou econômico-jurídicas, para que se justifiquem os efeitos dela decorrentes.

No que diz respeito às pessoas jurídicas, passando para o plano dos efeitos. importa destacar a divisão afirmativa de ativos, na expressão de alguns, ou seja. o fatu de que a barreira criada pela personificação do grupo impede que credores particulares de seus membros exerçam pretensões creditórias sobre ativos da pessoa jurídica, outro sujeito de dircito. Além desse a personificação produz, ainda, divisão defensiva dos ativos na medida en que prevê a limitação da responsabilidade dos membros por obrigaçõus da pessoa jurídica. A ordem de prioridades estabelecida para que os credores, sejam eles particulares dos membros quanto os da pessoa jurídica, satisfaçam suas pretensões sobre certo conjunto de bens é efeito inconteste da personificação. ${ }^{10}$

Sobre a importância para o desenvolvimento social, nota-se que a origem recente das sociedades por ações, que, aliás, pode ser estendida para sua origem mais remota, a formação das companhias de navegação da Idade Média, liga-se diretamente à noção de separação de riscos. de sua pulverização. A exigência. para reunir grandes volumes de recursos era separar riscos, seja para pulverizar os gerados no exercício de atividade cconômica quanto para não somar estes aos inerentes a atividades nãoeconômicas exercidas por seus organizadores. Essa exigência que levou à separação patrimonial e à criação de um patrimônio autônomo, o da sociedade. resultou do reconhecimento pelo Estado de serem as sociedades pessoas jurídicas.

A associação da idéia de privilégio, limitação da responsabilidade patrimonial ao montante investido" que, para Caio Mario da Silva Pereira, deriva do fato

9 FULLER, Lon L., ob. cil. p. 73 reproduz a seguinte noção de ficção juridica: "a device for utraining desired legal consequences or aroiding undesired legal consequences"

10 ALPA. Instituzioni, cit. p. 153. Il privilegio consiste essenzalmente nel'assegnare all ente riconosciuto, cioè alla persona giuridica. un parimónio separato da quello dei singoli membri. e capacita di agire separara rispelto a quella dei ingoli memhri. sicchè i terzi e i creditori per la dodisfazione delle loro pretese si possono rivolgere solo alli persona giuridica e non ai suoi m'mbri o ai suoi organi.

Istituzioni, cit., p. 153. 
e está na medida em que a capacidade das pessoas juridicas seja restrita aos fins perseguidos, ao que denomina princípio da especialização, ${ }^{12}$ está na basé desta análise.

A unificação de pessoas c bens, ou apenas bens, sob o manto da pessoa jurídica. depende do sistema de direito positivo que, para tanto, requer ato constitutivo, escopo ou fim lícito e cumprimento das formalidades legais, como o registro do ato constitutivo no registro competente. Segundo Fuller, essa unificação de pessoas e bens nada mais $\dot{i}$ do que uma ficção mediante a qual se toma como unidade o que é múltiplo para chegar a determinados fins e obter outros tantos efeitos.

Da concepção de pessoas jurídicas como ficção legal, o ordenamento positivo brasilciro reconhece, no campo do Direito Privado, as socicdades, as associações e as fundações, espécies de organização caracterizadas por processos de constituição e organização interna próprios e bem desenhados. Comum às três espécies de pessoas jurídicas é a existência, sempre, ou de um conjunto de pessoas ou de um conjunto de bens ou da combinação dos dois. conjuntos esses tomados como unidade. Nem por outra razão entende Caio Mario da Silva Pereira que a constituição de uma pessoa jurídica requer a conjunção de três requisitos: "a vontade humana criadora, a observância das condições legais de sua formação e a liceidade de seus propósitos" 13

A pessoa juridica serve para unificar conjuntos - de pessoas ou de bens esta a visão tradicional do instituto. Porém, ao definir um novo sujeito de direito também promove a separação de riscos econômicos que recaem sobre pessoas no exercício de atividades econômicas. Claro que a probabilidade de concretização do risco está diretamente relacionada com o tipo de atividade, razão pela qual é preciso conhecer a que se destina cada pessoa juridica, qual seu escopo de vez que o conjunto - de bens ou de pessoas - deverá estar, funcionalizado para alcançá-lo. As pessoas jurídicas podem ser classificadas segundo o elemento unificador que predomina na formação do conjunto, isto é, nas fundações os bens, nas associações as pessoas e, nas sociedades, a combinação de ambos.

Das pessoas juridicas ocupa-se o Código Civil a partir do art. 40. São classificadas em pessoas jurídicas de Direito Público, interno ou externo, e de Dircito Privado, as qui interessam ao presente e estas estão nomeadas no art. 44. Fundações, associações e sociedades.

12 PEREIRA. Caio Mario da Silva Instiniçōes de Direito Civil. 19. ed. Rio de Janeiro: Forense, s.d. v. I, p. 196.

13 Ob. cit., p. 186. 
O discurso começa, por simples facilidadu metodológica, dada a menor complexidade sob esse ponto da questão, a separação de riscos, inicia-se com as pessoas jurídicas fundações e associações.

Dispõe o art. 62 do Código Civil que o instituto jurídico fundação resulta de dotação de bens livres de uma pessoa para que sejam utilizados na consecução de determinado fim o qual, a teor do parágrafo único, somente poderá ser religioso. moral. cultural ou assistencial. A instituição da fundação e seu reconhecimento como sujeito de direito separa patrimônios e extrema riscos. Parte do ativo do patrimônio do instituidor é transferida para uma outra e nova pessoa criada para certo e determinado fim recebendo os buns que anteriormente integravam outro patrimônio os quais são, dessa forma, c por especificação do instituidor, funcionalizados para atingir um escopo que pode ser cultural, religioso, educacional, ou qualquer outro, inclusive a prestação de serviços a terceiros mediante remuneração.

Sendo dois os patrimônios, independentes entre si, sob diferentes titularidades, elimina-se o risco de credores particulares do instituidor exercerem pretensão sobre os bens transmitidos ou transferidos à fundação: igualmente credores da fundação não poderão exercer pretensão sobre os bens remanescentes (particulares) do instituidor. Após a transmissão da propriedade dos bens destinados à fundação nem mesmo seus administradores poderão exigir que outros ativos pertencentes ao instituidor sejam transferidos à fundação ainda que a consecução do seu escopo fique prejudicada.

Associações, forma de organização de pessoas i bens para lins nãoeconômicos, fins não-lucrativos, cujo negócio de criação é o contrato plurilateral, negócio de estrutura aberta, de organização da imputação, exatamente como se dá com as sociedades, destas se afastam em virtude de não perseguirem finalidade lucrativa para partilha dos resultados entre os membros.

O teor do art. 53 do Código Civil está eivado de ambigüidades. Primeiro, porque o legislador parece ter hesitado no explicar que tipo de união serve para organizar pessoas para exercerem alguma atividade. Depois, porque ao se relerir a fim nãoeconômico induz a que se imagine ser dispensável qualquer contribuição financcira ou econômica. Terceiro, porque o parágrafo único, ao dispor que entre mumbros não hả direitos e obrigações mútuos, parece considerar que nas associações cada qual pode fazer o que quiser. Nada disso é real.

Nas associações, tal como nas sociedades, não está descartada a possibilidade de serem exigidas contribuições aus membros seja para a organização da associação scja para sua posterior manutenção.Minimamente despesas com registro são de responsabilidade de associados. 
Quanto ao serem destinadas a fins não-econômicos, entunda-se que o que não se deseja é a perseguição de lucros para posterior partilha até porque muitas associações têm como objeto (ou escopo) fins que podem ser valorados economicamente.

Nem todas as associações são organizadas para prestar serviços ou gerar beneficios para terceiros; há aquelas cujos benefícios são destinados ou atribuidos apenas aos membros. Caso de clubes em que freqüência se restringc aos sócios cuue. de seu lado, pagam mensalidades (ou, de alguma outra forma, contribuem para a manutenção da associação). Claro que esses beneficios têm valor econômico: quando se garante a certas pessoas o privilégio de terem acesso a bens ou praticarem atividades em locais de acesso restrito. Veja-se a preferência na aquisição de ingressos para temporadas artisticas, musicais, teatrais, líricas, participação em eventos. Se a comunidade não considerasse haver em tais prioridades algum valor que pode ser expresso em moeda, a que serviriam? Matéria de Ascarelli quando analisa o contrato plurilateral põe a nu peculiaridades de certas associações que se aproximam das sociedades.

Quando se condiciona o gozo das facilidades postas à disposição dos membros a alguma contrapartida, alguma contribuição ou, deixando o membro de contribuir poder-lhc-ão ser impostas sanções entre as quais a proibição de gozar dos benefícios oferecidos aos membros indo até a exclusão do corpo de associados.

Nesse caso como é que se aplica a norma do parágrafo único ao art. 53 , cuja redação é: "Não há, entre os associados, direitos $\epsilon$ obrigações reciprocos"? Como escapar da noção de que, em muitas associações há, sim. deveres e direitos recíprocos entre membros? Em alguma medida existe relação entre sócios c associação e destes entre si, embora se possa admitir que a reciprocidade seja atenuada.

A dúvida que emerge da separação agora positivada entre sociedades e associações, do ponto de vista pragmático era necessária? Quais os benefícios dela decorrentes? Em que medida a disciplina das associações reduz custos de transação, evita opurtunismos, melhora a qualidade das relações entre membros?

As respostas serão oferecidas se e quando disputas internas ou com terceiros não-membros forem julgadas pelos Tribunais.

No que tange às sociedades que, anteriormente, vinha disciplinadas, a sociedade civil no Código Civil, de 1916, e as comerciais, tanto no Código Comercial, de 1850, quanto em legislação extravagante, as sociedades por quotas de responsabilidade limitada pelo Decreto n. 3.708/19/9 e as companhias na Lei n. 6.404/1976, foram, as formas primitivas de socicdades comerciais. excluida a sociedade de capital e trabalho. insertas no ('ódigo (ivil, tal como a limitada cujas rugras foram substancialmente 
modificadas. Quanto à antiga sociedade civil, desaparcceu entrando para $\cap$ rol de sociedades, a simples estruturada de maneira mais rígida do que a anterior.

A expressão sociedade simples tem dois sentidos: de um lado representa um tipo de socicdade personificada que se pretende seja a estrutura básica desse modelo de contrato; de outro indica quaisquer sociedades que não exerçam atividades empresárias.

No art. 981, que reproduz parcialmente o art. 2.247 do códice civile, de 1942, o legislador define o negócio sociedade como o contrato celebrado entre pessoas que, reciprocamente se obrigan: a contribuir com bens ou serviços para o exercicio de atividade econômica e a partilha entre si dos resultados. Redação menos adequada do que a do peninsular que, na expressão "exercicio em comum de atividade econômica" evidencia a necessidade de comınhão de escopo, o fim comum que aproxima as pessoas que facilita seu grupamento.

A simples idéia de recíproco se confunde, no direito das obrigações, com os tradicionais esquemas do do ut ciês, do ut facias ou facio ut facias que não expressa bem a idéia de cooperação, de combinação de esforços para fím comum que está na base das sociedades, contratos de estrutura aberta, de organização, em que são disciplinadas as relações internas e previstas as ações externas da unidade.

É impar o papel descmpunhado pelas sociedades no tráfico e no desenvolvimento econômico. Por sua aptidão para concentrar recursos c esforços, pela facilidade de captar energias e capitais para a realização de operações financeiras, comerciais, industriais, além da perseguição de outras vantagens, ${ }^{14}$ não há como dispensálas. A colaboração dos membros para o funcionamento das sociedades pode ser pessoal, esforços, trabalho, em recursos uu bens, ou ambos, no que não difere do que se prevê em relação aos membros das associações.

Pela disciplina do Código Civil são sociedades todas as organizações que visam a fins econômicos, perseguem resultados econômico-financciros para partilha entre seus membros. Curial, então, que na sua análise, seja incluida a perspectiva econômica.

$\mathrm{Na}$ visão dos economistas as empresas e sociedades impresárias são consideradas feixes de contratos ou nexos de contratos que, complementando os murcados, reduzem custos de transação. Desejáveis, porque criam riquezas e bem-estar. Ronald H. Coase apontou, em :937, 's a importância da organização de empresas como instrumento para reduzir custos de transação, organização que complementa mercados. Harold Demsetz e Armen Alchian entendem que empresas, organizações hierárquicas.

I4 TRABUCHI, ob. cit., p. 372 diz que L'impresa sociale é costituitu da piu soggetti che sie riumiscono côn vincolo contrattuale per ottenere insieme dei vamagi.

is The Natur of the Firm - atualmentc em The Firm, The Market and The Law - The University of Chicago Press - 1990 . 
nexo de contratos, visam a tornar mais eficiente a produção. criando incentivos para todos a elas ligados.

O Código Civil, no que diz respeito às sociedades empresárias, se ocupa das personificadas, uma vez que a sociedade em conta de participação não está relacionada entre os tipos que podem revestir as empresas coletivas.

Sobrc a personificação das sociedades empresárias, o quc se costuma ler : que, por conta desse reconhecimento - e no direito estrangeiro, apenas às limitadas ćàs anônimas é conferida a personalidade jurídica, que o novo sujcito de direito não se confundc com os sócios e que a personificação leva à separação patrimonial e, em alguns casos, à limitação da responsabilidade patrimonial dos sócios por obrigações da sociedade.

A noção de patrimônio, universalidade de direito, complexo de relações jurídicas de uma pessoa. dotadas de valor econômico. (art. 91 do NCC), leva ao reconhecimento de que há uma relação direta entre pessoa. sujeito de direito, essa universalidade - cada pessoa tem um patrimônio e não há patrimônio sem titular.

Porém, essa teoriz geral aplicada às sociedades, deixa em segundo plano outro efeito, não menos importante, derivado da personificação que tem que ver com separação ou segregação de riscos. Se a sugregação de riscos constitui outra facc da separação patrimonial ou se esta é conseqüência do reconhecimento daqucla, não há como afirmar com segurança. Possivel que a separação de riscos esteja na origem recente da sociedade por ações, porque ao reconhecer a limitação da responsabilidade dos sócios ao montante do investimento feito. limitava o risco assumido.

A separação patrimonial e a decorrente limitação da responsabilidade pessoal de sócios por obrigações da sociedade facilita receber investimentos de muitas pessoas que, somados, permitem a cômoda organização de atividades - e isso vale para sociedades capital intensivas, para aquelas em que o investimento é de longo prazo de maturação e para aquelas em que, por operarem em setores de tecnologia, apresentam clevado risco de insucesso - . A fragmuntação do risco serve como incentivo para investidores que se mostrem propensos a participar desses investimentos.

Exceto por espírito aventureiro, dificilmente alguém compromete em investimentos econômicos, a totalidade de seus recursos ou bens. Se há risco de ganho existe o de perda, e apenas considerando-se um elemento subjetivo - aversão ou propensão ao risco - é que se poderia levar adiante certos emprcendimentos econômicos.

A segregação do risco aparece de forma mais evidente nas grandes sociedades, porque demandam maiores somas dos investidores e os resultados, nem sempre são positivos, nem sempre haverá lucro. Ora se as perdas recaíssem sobre todos os 
membros ou mesmo sobre alguns deles apenas, dificilmente seriam organizadas as grandes anônimas, porque os riscos individuais, isto é, a possibilidade de que qualquer credor social viesse a exercer pretensão sobre bens particulares dos acionistas, configuraria estímulo nugativo à participação em operações econômicas.

$\mathrm{O}$ que se demanda dos sócios é que envidem esforços (ou que não atrapalhem o exercício da atividade), contribuam fundos ou bens para que, obtidos resultados, sejam eles divididos entre os sócios. A reciprocidade fica no plano interno uma vez que a sociedade não-responde com seus bens por obrigações pessoais dos sócios bem assim nenhum deles responde perante credores de outro(s) por obrigações estranhas à sociedade.

Riscos da sociedade afetam aos sócios diretamente e, por via indireta aos seus credores. Áqueles porque suas contribuições para o capital social podem desaparecer. A estes porque a insolvência afuta a capacidade de cumprir as obrigações e, portanto, reduz a probabilidade de satisfação do crédito. Quando a sociedade é personificada - caso das sociedades empresárias, da simples e da cooperativa - pode haver, ou-não, plena autonomia patrimonial. Nesse caso os riscos ficam concentrados na pessoa juridica. Se a autonomia patrimonial for imperfeita ou incompleta. os riscos concentrados na sociedade serão transferidos, secundariamente, aos sócios, um, alguns ou todos, dependendo do tipo de sociedade de que se trate.

Retomando o que se expôs acima, a divisão de ativos e riscos que separa credores pessoais dos credores da pessoa jurídica, facilita acompanhar e monitorar os efuitos dos riscos que podem afetar cada um dos sujeitos - positivos, ou-não - sociedades personificadas e sócios individualmente. Isso também reduz custos de transação e, em muitos casos, custos de financiamento uma vez que não se confundem e não exercem pretensões sobre o mesmo conjunto de ativos os credores por obrigações sociais com aqueles pessoais dos sócios. A concorrência entre esses diferentes tipos de credores sobre um mesmo acervo pode dificultar a avaliação dos riscos de crédito. É que. se os credores sociais obtêm informações sobre o negócio, os credores pessoais dos sócios as terão apenas mediante acompanhamento de publicação de balanços ou outros documentos societários. De outro lado aos credores sociais é mais difícil obter informações relativas às finanças pessoais dos sócios e administradores de socicdades em relação aos credores particulares dos sócios.

A segregação de riscos associada à divisão de créditos, à partilha positiva dos ativos, tende a reduzir custos financeiros c, dessa forma, tornar as operações de financiamento mais eficientes. 
O termo risco, medida estatística, desvio padrão ou variância, méde a probabilidade de ocorrência de um evento ou resultado. No tocante à empresa o resultado consiste no êxito ou insucesso do empreendimento. Tanto é risco a apuração de lucros (resultado positivo) quanto de prejuízos (resultado negativo); a associação de risco à só possibilidade de perda, de fracasso, de perigo, que é a comum, não é o móvel deste estudo que foca a separação de riscos e como a ficção da personalidade jurídica de sociedades atende a tal desiderato.

Admitindo-se que a geração de riquezas, a promoção social e o crescimento econômico dependem, fundamentalmente, dos resultados da atividade econômica, da tutela dos bens a ela vinculados, liberdade de organização é crucial para que obter resultados favoráveis. Não pode o legislador impor barreiras, salvo as de interesse público, que dificultem ou onerem o exercício da atividade econômica. Ao revés. o empenho na criação dos incentivos coretos é vital, porque quando se facilita o exercício de atividades geradoras de riquezas, produtoras de benefícios compartilháveis entre muitas pessoas, remuneratórias dos esforços de investidores que tomam riscos c respeitantes do interesse difuso que é a comunidade na qual se inserem, atende-se a relevante função social desempenhada pelas organizações econômicas.

A liberdade de organizar atividades, de arriscar deve ser estimulada porque é boa para a comunidade; indesejável é permitir se arrisque poupança alheia ao fazê-lo. Impor restrições relativamente à disposição de bens e à organização de sociedades nem sempre é a melhor alternativa para salvaguardar certos patrimônios. Não interessa permitir a destruição de valor assim como não interessa estimular o recurso a soluções ardilosas. artificiosas, para obter o efeito de separar riscos.

Agentes propensos a risco adotarão medidas cujos efeitos serão danosos para si e, iventualmente, para terceiros. Os que agem honestamente, seguem padrões socialmente desejáveis, movem-se segundo incentivos corretos, serão prejudicados se decisões de politica legislativa impuserem freios onde eles não são necessários. Nesse caso faz-se uma espécie de justiça às avessas. perversa e que reduz bem-estar para a comunidade.

De todas as pessoas jurídicas de direito privado as sociedades são as que, de longe, maiores atenções recebem. Nesse negócio a conjugação de esforços e recursos que se aplica na formação da base material para o exercicio da atividade econômica e o risco são indissociáveis.

Limitada a análise às sociedades empresárias, antigas suciedades comerciais, enfrenta-se o fato de que a unificação do direito das obrigações e a inclusão. no Código Civil dessa matéria (Livro II - Do Direito de Empresa), divergindo de quem 
entende que o Direito Comercial desapareceu, reproduz-se pensamento de Giorgio Oppo quando trata da questão da unificação do direito privado italiano e a autonomia do Direito Comercial.

Oppo, ${ }^{16}$ entende que a autonomia do Direito Comercial, anteriormente fundada na ordem, na hierarquia das fontes, um pressupostos objetivos e subjutivos, sobre regras gerais reconduzidas à matéria de comércio, sobre os contratos típicos, deve ser, depois da unificação do Direito Privado na Itália, encontrada nos princípios de direito comercial dentro do sistema de Direito Privado, em realidade como um direito dos mercados.

Se Direito Comercial é o direito dos mercados, é preciso pensar o conjunto de relações jurídicas impessoais e repetidas de maneira igual entre diferentes pessoas. Isso implica que nada obstante a unilicação do direito das obrigações, há duas vertentes que se põım diante do operador do direito: a individualista, pontual, que é própria do civilista, e a que trata do exercício de atividades econômicas, dinâmica, e escolher um dos eixos para, ao redor dele, construir a disciplina.

Para Guido Alpa a criação de entes é típica do mundo moderno e se dá como resposta a exigências econômicas, ${ }^{17}$ vale dizer, tanto pela especificação positiva ou negativa de ativos e sua destinação preferencial para a satisfação de obrigações, a personificação é fundamental no direito de empresa.

A partilha de ativos direcionados para certas atividades exercidas por outra pessoa jurídica permite isular operações o que, é interessante tanto no plano da segregação do risco quanto no de prestação de garantias que podem recair apenas sobre os ativos pertencentes àquele sujeito. As pessoas jurídicas, por definirem um centro de imputação, têm capacidade para agir e manifestar-se externamente.

$E$, no que concerne ao direito de empresa, há visível descompasso entre o descjável e o positivado no novo ('ódigo Civil. O engessamento da autonomia privada, cada vez mais presa a regras impeditivas ao frear a criatividade dos agentes econômicos vai em direção oposta a certos princípios constitucionais como os da livre iniciativa e livre concorrência. Pior que isso é que, se isso vier a diminuir a utilidade social criada pelo exercício da atividade empresarial, perdem todos.

As balizas adotadas na análise da matéria empresarial devem compor direito e fundamento econômico, ambos pilares para a melhor compreensão e aplicaçâo das normas aos fatos sociais. O Código Civil não foi nessa direção e muilas de normas

\footnotetext{
16 OPPO, Giorgi. Principi. In: TRATTATO di Dirirllo Commerciale. Diretto da Vincenzo Buonocore. Torino: G. Giapichelli Editore, 2001 . Sezione I-Tomo I-p. 35 e segs.

17 Oh. cil., p. 153.
} 
deixaram para trás instituições e normas socialmente aceitas para mantur um rigidez conceitual que não-atende aos desejos da comunidade.

A coerência no trato da unicidade patrimonial deixa em segundo plano questões que se referem ao exercício da empresa que, na vigência de dois Códigos de direito privado, encontravam caminhos específicos. Como se o legislador de 2002 se apegasse a uma visão rígida, quase maniqueísta, congclando esquemas que não se compadecem com a noção de que o direito é um sistema aberto e que, no trato das questões, a recepção de práticas sociais é constante.

Essa visão conservadora está patente seja no disposto, melhor, na proibição imposta no art. 997 do Código Civil, Lei n. 10.406/2002 quanto na não-recepção das sociedades unipessoais, limitada à subsidiária integral. cuja disciplina está na Lei n. $6.404 / 1976$.

Sobre a proibição de constituição de sociedades entre cônjuges quando o regime de bens do casamento seja o da separação obrigatória ou o da comunhão universal, o que se lê a respeito é que a norma apenas confirma matérias previstas em outros dispositivos legais. A vedação que atinge pessoas casadas pclo regime da separação obrigatória de bens, conviria ancorá-la aos casos em que esse regime é imposição legal. Se, por outro lado, for voluntário, a proibição deveria ser afastada dado que, mesmo sem mudar o regime de bens do casamento - faculdade que o legislador admitiu - deveria impedir que os cônjuges optassem por, indiretamente, estabelecer comunicação parcial de bens? Que prejuízos adviriam para terceiros, notadamente credores de cada um deles, se à constituição da sociedade fosse dada ampla publicidade? Ou, ainda, se aos credores anteriores ficasse garantido o direito de satisfazerem seus créditos, à falta de bens pessoais, sobre os da sociedade?

A quebra do princípio da separação de bens será irregular quando o regime da separação de bens for o legal, vez que nesta o que se pretende é "proteger" os mais idosos ou a confusão com bens de herança da família, caso de viúvos que se casem antes da partilha.

Sobre a comunhão total o espírito é o inverso, evitar a separação de bens de um mesmo patrimônio comum especializando alguns. Poder-se-ia alegar que o patrimônio de afetação resolve o problema. Talvez sim, mas a transferência de bens para uma pessoa jurídica, notadamente quando destinados ao exercício de atividade empresária, protege os bens remanescentes da pretensão dos credores da atividade. É a tal divisão positiva de ativos atrás apresentada.

Pensando em eventuais desvios de comportamento, ou seja, de burla para subtrair bens do patrimônio e com isso prejudicar credores, lembra-se o caso clássico 
Solomon v. Solomon de desconsideração da persunalidade jurídica (cuja decisão final foi contrária à tese). Sociedade anônima formada por sete pessoas, todos membros da mesma familia, o casal e cinco filhos, preenchendo, formalmente, os requisitos legais. Em dado momento, sem receber os valores devidos, os credores foram surpreendidos com a declaração de insolvência quando verificaram que o sr. Solomon, era titular de créditos privilegiados ou garantidos cujo pagamento prioritário deixaria os demais credores sem possibilidades de terem suas pretensões satisfeitas.

Notc-se que a questão nada tinha que ver com a separação patrimonial, por ser aquela uma sociedade entre membros da mesma família mas com o fato de que, um dos acionistas. que conhecia a situação econômico-financeira do negócio, ao invés de aportar capital. fizera empréstimo à sociedade, os quais tinham garantias. $u$ que lhes dava prioridade no pagamento. A situação era de assimetria informacional e, em especial, de uso de forma jurídica que permitia aos acionistas Solomon limitarem sua responsabilidade pessoal pelas obrigações da sociedade. Mau uso da divisão positiva de ativos, situação que, menos do que juridicamente irregular era moral e eticamente inaceitável.

Dessa forma se, por exemplo, cônjuges cujo regime de bens do casamento for o da separação obrigatória de bens, resolvessem constituir uma sociedade na qual, mediante combinação os bens fossem todos contribuídos por um deles e esforços pelo outro, o desvirtuamente do uso da personificação tem mesma característica do caso Solomon. Chegar à comunhão narcial, (ou total), contra vedação legal. A aplicação da norma do art. 50, desconsiderando-se a personalidade

Se a personificação de grupos de pessoas ou conjuntos de bens organizados para determinadas finalidades tem função socialmente desejável, essa função está na segregação de riscos que são indissociáveis da atividade empresarial. Por isso que a criatividade dos agentes econômicos leva a outra forma de proteção de bens: além de fragmentar ou separar riscos com a personificação de sociedadis, novos negócios aparecem visando. precipuamente, para minimizar ou transferir riscos que são as operações de hedge, formando barreiras contra os efeitos do riscos ligados à volatilidade de preços.

Curioso é que. enquanto o legislador se apega a conceitos em matéria de scparação patrimonial, aqueles que eram dogma no século XIX, contratus antes equiparados a jogo ou aposta, os denominados derivativos, são "legalizados em 2002" Como se a importância da funçăo econômica da personificação fosse esquecida porque, afinal. trata-se de mera ficção juridica.

São Paulo, novembro de 2005 


\section{Referências}

COASE, Ronald H. The Firm, the Market, and the Law, Chicago: University of Chicago Press, 1990.

FULLER. Lon L. Legal Fictions. Stanford: Stanford University Press, 1986.

GALGANO, Francesco. /l Rovescio del Diritto. Milano: Giuffrè Editore, 1991.

MONTEIRO, Washington de Barros. Curso de Direilo Civil: parte geral. São Paulo: Saraiva, 1966.

OPPO, Giorgi. Principi. Torino: G. Giappichelli, 2001. Sezione I, Tomo I.

PEREIRA, Caio Mario da Silva. Insituições de Direito Civil. 19. ed. Rio de Janeiro: Forense, I998. v. I.

TRABUCCHI, Alberto. Istituzioni di Diritto Civile. 40. ed. Padova: Cedam, 2001. 